\title{
Immune response in breast cancer brain metastases and their microenvironment: the role of the PD-1/PD-L axis
}

Renata Duchnowska ${ }^{*}$, Rafał Pęksa ${ }^{2}$, Barbara Radecka ${ }^{3}$, Tomasz Mandat ${ }^{4}$, Tomasz Trojanowski ${ }^{5}$, Bożena Jarosz ${ }^{5}$, Bogumiła Czartoryska-Arłukowicz ${ }^{6}$, Wojciech P. Olszewski ${ }^{7}$, Waldemar Och ${ }^{8}$, Ewa Kalinka-Warzocha ${ }^{9}$, Wojciech Kozłowski ${ }^{10}$, Anna Kowalczyk ${ }^{11}$, Sherene Loi ${ }^{12}$, Wojciech Biernat ${ }^{2}$, Jacek Jassem ${ }^{11}$ and for the Polish Brain Metastasis Consortium

\begin{abstract}
Background: A better understanding of immune response in breast cancer brain metastases (BCBM) may prompt new preventive and therapeutic strategies.

Methods: Immunohistochemical expression of stromal tumor-infiltrating lymphocytes (TILs: CD4, CD8, CTLA4), macrophage/microglial cells (CD68), programmed cell death protein 1 receptor (PD-1), programmed cell death protein 1 receptor ligand (PD-L)1, PD-L2 and glial fibrillary acid protein was assessed in 84 BCBM and their microenvironment.
\end{abstract}

Results: Median survival after BCBM excision was 18.3 months (range 0-99). Median number of CD4+, CD8+ TILs and CD68+ was 49, 69 and 76 per $1 \mathrm{~mm}^{2}$, respectively. PD-L1 and PD-L2 expression in BCBM was present in $53 \%$ and $36 \%$ of cases, and was not related to BCBM phenotype. PD-1 expression on TILs correlated positively with CD4+ and CD8+ TILs ( $r=0.26$ and 0.33 ), and so did CD68+ ( $r=0.23$ and 0.27 , respectively). In the multivariate analysis, survival after BCBM excision positively correlated with PD-1 expression on TILs (hazard ratio $(H R)=0.3$, $P=0.003), C D 68+$ infiltration ( $H R=0.2, P<0.001)$, brain radiotherapy $(H R=0.1, P<0.001)$, endocrine therapy $(H R=0.1, P<0.001)$, and negatively with hormone-receptor-negative/human epidermal growth factor receptor 2 (HER2)-positive phenotype of primary tumor ( $H R=2.6, P=0.01)$, HER2 expression in BCBM $(H R=4.9, P=0.01)$.

Conclusions: PD-L1 and PD-L2 expression is a common occurrence in BCBM, irrespective of primary tumor and BCBM phenotype. Favorable prognostic impact of PD-1 expression on TILs suggests a beneficial effect of preexisting immunity and implies a potential therapeutic role of immune checkpoint inhibitors in BCBM.

Keywords: Brain metastases, Breast cancer, PD-1, PD-L, Lymphocytes

\section{Background}

Breast cancer has not been traditionally considered an immunogenic cancer type. However, there is an increasing body of evidence suggesting that an effective immune response may greatly impact on the clinical behavior of this malignancy. Tumor lymphocyte infiltration is associated with favorable prognosis in early triple-negative and human epidermal growth factor receptor type 2 (HER2)-positive

\footnotetext{
* Correspondence: rdtt@wp.pl

${ }^{1}$ Department of Oncology, Military Institute of Medicine, Szaserów St 128, 04-141 Warsaw, Poland

Full list of author information is available at the end of the article
}

breast cancer phenotypes [1-4] and may influence the response to systemic therapies [3-6]. Information on the association between the immune host response and the colonization of the brain by tumor cells is scarce. The central nervous system (CNS) has long been considered an immunologically privileged site [7]. Actually, CNS is an immune specialized site under a tight regulatory control network linking microglia, astrocytes and lymphocytes [8].

Brain metastases in preclinical and clinical models are characterized by high proliferation, apoptosis, and inflammatory response in the form of surrounding extensive 
reactive gliosis [9]. It is postulated that the reactive astrocytes reduce apoptosis mediated by the cytotoxic agents by sequestering calcium from the cytoplasm of tumor cells or by secreting metastasis-stimulating chemokines [10]. In the inflammatory and degenerative processes, CNS reactive glial cells actively participate in the restimulation of $\mathrm{T}$ cells through the secretion of some chemokines $[9,11,12]$. This increases the influx of regulatory $\mathrm{T}$ cell $\left(\mathrm{T}_{\text {reg }}\right)$ lymphocytes, resulting in silencing of the immune response.

The programmed cell death protein 1 receptor (PD-1) and its ligands, programmed cell death protein 1 receptor ligand (PD-L) 1 and PD-L2, also known as B7-H1 and B7-DC, respectively, play a crucial role in the induction and maintenance of peripheral tolerance, and protect tissues from autoimmune attack [13]. The PD-1/PD-L axis is also a key getaway pathway serving in many cancers as an "immune control" [14, 15]. Several studies suggest that immune response to malignant processes in the brain may be related to the type of cancer [16-19]. Better understanding of the local immune response accompanying brain metastases (BM) may pave the way to the development of novel preventive and therapeutic strategies in breast cancer patients. This retrospective study aimed to assess the correlation between selected parameters of immune response in breast cancer brain metastases (BCBM) and their impact on overall survival.

\section{Methods}

\section{Study population and data collection}

This study was approved by the Institutional Review Board of the coordinating center, the Military Institute of Medicine in Warsaw, Poland. The study group included breast cancer patients who underwent excision of BCBM (Table 1). The patients were diagnosed and treated between 1990 and 2014 in eight oncology centers in Poland. Demographic, clinicopathologic, and clinical follow-up data were extracted from medical records. All data were coded to secure full protection of personal information, therefore, patient consent was not sought.

\section{Pathologic analysis}

The starting material from each patient was an archival formalin-fixed, paraffin-embedded (FFPE) specimen obtained at surgery from the primary breast tumor and BCBM. The pathologic diagnosis was confirmed by a Board-certified pathologist (RP or WB) who reviewed FFPE tissue sections stained with hematoxylin and eosin. A representative paraffin block from each specimen was chosen for immunohistochemical analysis (IHC). In patients with more than one BCBM, only the single most representative lesion was subjected to analysis.

\section{Immunohistochemical staining}

All samples were re-stained and IHC-based expression for estrogen receptor alpha $(E R \alpha)$, progesterone receptor (PR) and HER2 was determined in the central laboratory by two pathologists (RP and $\mathrm{WB}$ ) who were blinded to the original assessments and to expression in the paired samples. Then, BCBM and the adjacent brain microenvironment were subjected to analysis of stromal tumor infiltrating lymphocytes (TILs) (CD4+, CD8+, CTLA4+), CD68+ cell infiltration, expression of PD-1, PD-L1, PD-L2, and glial fibrillary acid protein (GFAP). The staining was performed according to the manufacturers' protocols (Table 2). The TILs and CD68+ cells were scored under a light microscope at a magnification of 400 (ocular $\times 10$ with objective of $\times 40$ ), corresponding to a total area of $1 \mathrm{~mm}^{2}$ on full slides. As TILs are predominantly present in stromal parts of BCBM and are a rare occurrence in other BCBM compartments, we have consistently used the term "stromal TILs". TILs were considered PD-1+ if cytoplasmic staining was found in at least $1 \%$ of cells, irrespective of staining intensity. PD- 1 staining was assessed in lymphoid cells, which were identified basing on morphologic features and previously performed staining for/CD4+ and CD8+, with negative results (0) or positive results (1). Due to lack of standardization criteria of PD-L expression positivity and possible intratumoral heterogeneity, PD1-L1 and PD-L2 were assessed in the whole tissue sections using the semiquantitative staining $\mathrm{H}$-score, which accounts for the quantitative and qualitative features of the reactions. The intensity of staining was defined as weak (1), moderate (2), or strong (3). The intensity of the reaction was determined in a percentage of positive cells. The $\mathrm{H}$-score was calculated for each biomarker by the formula:

$3 \times \%$ Strong cellular staining (cytoplasmic, nuclear and/ or membranous) $+2 \times \%$ Moderate staining $+\%$ Weak staining

This gave a range of $0-300$. Figure 1 shows positive control staining for PD-1, PD-L1 and PD-L2.

\section{Statistical analysis}

All statistical analyses were performed using STATA software version 11. Statistical significance was defined as $P<0.05$. We tested correlation between parameters of immune response in $\mathrm{BCBM}$ and the brain microenvironment and GFAP, PD-1, PD-L1, PD-L2, TILs (CD4+, CD8+, CTLA4+) and CD68+ cells (listed in Table 3), and assessed their prognostic relevance. This analysis included all available clinical and pathological variables (Table 1). Due to the retrospective and multicenter nature of the study we were unable to include BCBM size and accompanying cerebral edema in the analysis, or the use of steroids and diuretics. Categorical and continuous variables were compared using Pearson's chi-squared test $\left(c^{2}\right)$, Spearman's $r$ rank test and 
Table 1 Patient characteristics

\begin{tabular}{lll}
\hline Variable & $N$ & $\%$ \\
\hline Primary tumor and matched brain metastases $(N=84)$ & & \\
Primary tumor histology & 70 & 83 \\
Ductal & 7 & 8 \\
Lobular & 2 & 2 \\
Ductal and lobular & 2 & 2 \\
Other & 3 & 4 \\
Uncertain & &
\end{tabular}

Primary tumor grade

$\begin{array}{lll}1 & 6 & 7 \\ 2 & 35 & 42 \\ 3 & 39 & 46 \\ \text { Unknown } & 4 & 5 \\ \text { Primary tumor ERa (IHC) } & & \\ \text { Negative } & 42 & 50 \\ \text { Positive } & 42 & 50 \\ \text { Primary tumor PR (IHC) } & & \\ \text { Negative } & 52 & 62 \\ \text { Positive } & 31 & 37 \\ \text { Unknown } & 1 & 1 \\ \text { Primary tumor HER2 (IHC) } & & \\ 0 & 21 & 25 \\ 1 & 18 & 21 \\ 2 & 9 & 11 \\ 3 & 36 & 43\end{array}$

Primary tumor HER2 amplification (FISH; performed in 16 cases)

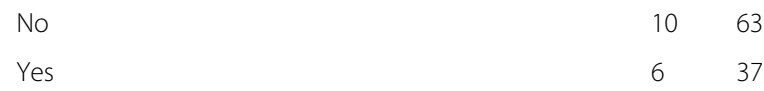

Primary tumor phenotypes

HR-/HER2-
HR+/HER2-
HR+/HER2+
HR-/HER2+
BCBM phenotype
HR-/HER2-
HR+/HER2-
HR+/HER2+
HR-/HER2+
Unknown
Radiotherapy

No

Adjuvant

Definitive

Palliative

Combination thereof
Table 1 Patient characteristics (Continued)

\begin{tabular}{lll}
\hline Unknown & 3 & 6 \\
Chemotherapy & & \\
Induction & 52 & 62 \\
Adjuvant & 35 & 42 \\
For metastatic disease & 4 & 5 \\
Combination thereof & 36 & 43 \\
Unknown & 5 & 6 \\
Endocrine therapy & & \\
No & 42 & 50 \\
Adjuvant & 24 & 29 \\
For metastatic disease & 5 & 6 \\
Combination thereof & 11 & 13 \\
Unknown & 2 & 2
\end{tabular}

Trastuzumab in HER2+ patients (adjuvant or metastatic setting) before BCBM

$\begin{array}{lll}\text { No } & 19 & 47 \\ \text { Yes } & 20 & 50 \\ \text { Unknown } & 1 & 3\end{array}$

Type of first progression

Regional $\quad 5 \quad 6$

Distant

$75 \quad 89$

Local/regional and distant $\quad 3 \quad 4$

Unknown

Dominant site of metastatic disease

Soft tissue $\quad 3 \quad 4$

Bone $\quad 4 \quad 5$

$\begin{array}{lll}\text { Visceral } & 76 & 90\end{array}$

Unknown $\quad 1 \quad 1$

BCBM as first relapse

$\begin{array}{lll}\text { No } & 36 & 43\end{array}$

$\begin{array}{lll}\text { Yes } & 47 \quad 56\end{array}$

Number of BCBM

$\begin{array}{lll}1-3 & 20 & 24\end{array}$

$\begin{array}{lll}>3 & 10 & 12\end{array}$

Unknown $\quad 3 \quad 4$

BCBM sites

Cerebellum $\quad 22 \quad 26$

$\begin{array}{lll}\text { Parietal lobe } & 19 & 23\end{array}$

$\begin{array}{lll}\text { Frontal lobe } & 14 & 17\end{array}$

Temporal lobe $\quad 6 \quad 7$

$\begin{array}{lll}\text { Occipital lobe } & 8 & 10\end{array}$

Other $2 \quad 2$

Combination thereof $\quad 6 \quad 13$

Unknown $\quad 2 \quad 2$ 
Table 1 Patient characteristics (Continued)

\begin{tabular}{lll}
\hline Radiotherapy after BCBM excision & & \\
No & 15 & 18 \\
Yes & 63 & 75 \\
Unknown & 6 & 7 \\
Chemotherapy after BCBM excision & & \\
No & 38 & 45 \\
Yes & 37 & 44 \\
Unknown & 9 & 11
\end{tabular}

Endocrine therapy after BCBM excision in $\mathrm{ERa} / \mathrm{PR}+$ primary breast cancer

$\begin{array}{lll}\text { No } & 62 & 74 \\ \text { Yes } & 15 & 18 \\ \text { Unknown } & 7 & 8\end{array}$

Trastuzumab after BCBM excision in HER2+ primary breast cancer

$\begin{array}{lll}\text { No } & 32 & 78 \\ \text { Yes } & 8 & 20 \\ \text { Unknown } & 1 & 2\end{array}$

Lapatinib after BCBM excision in HER2+ primary breast cancer

$\begin{array}{lll}\text { No } & 14 & 17 \\ \text { Yes } & 8 & 10\end{array}$

Alive at last follow up

No

Yes

Age at breast cancer diagnosis; mean (range) years

Age at BCBM diagnosis; mean (range) years

Percentages for values of patient characteristics may not sum to 100 becau of rounding to full numbers. $N$ number, $E R a$ estrogen receptor alpha, $P R$ progesterone receptor, IHC immunohistochemical analysis, FISH fluorescence in situ hybridization, $H R$ hormone receptor, $H E R 2$ human epidermal growth factor receptor 2, $B C B M$ breast cancer brain metastases

the Mann-Whitney $U$ test. Overall survival (OS) was computed using the Kaplan-Meier method, starting from $\mathrm{BCBM}$ excision to the date of death or the last follow up. Univariate and multivariate analyses were performed using the log-rank test, Wilcoxon test, and Cox proportional hazard and logistic regression.

\section{Results}

\section{Patient characteristics}

The study group included 84 breast cancer patients who underwent excision of BM (Table 1). Based on ER $\alpha$, PR and HER2 expression, four primary tumor phenotypes were identified: hormone-receptor + and HER2- (23 cases), hormone-receptor + and HER2+ (21 cases), hormonereceptor- and HER2- (21 cases), and hormone-receptorand HER $2+$ (19 cases). Of these tumors $83 \%$ were invasive ductal carcinomas (no special type); $42 \%$ were grade 2 and $46 \%$ were grade 3: $50 \%$ were ER $\alpha$ - and PR-, $48 \%$ were HER2+ (IHC3+ or HER2 amplified by fluorescence in situ hybridization (FISH)). All patients underwent radical surgery for the primary tumor; $62 \%$ received neoadjuvant chemotherapy and $42 \%$ adjuvant chemotherapy, $32 \%$ received adjuvant radiotherapy and 19 (50\% of the 38 HER2+ cases) received adjuvant trastuzumab. The first manifestation of progression was distant metastasis in $89 \%$ of patients, with viscera being the most common dominant sites of metastatic disease. Fortyseven patients (56\%) developed BM as the first site of progression, $61 \%$ of whom presented with a single brain lesion at the time of excision. The mean age at BCBM diagnosis was 53 years (range 30-81). The median length of follow up in the entire population was 61.3 months (range 8.7-209 months). The median time to BCBM occurrence from first diagnosis of breast cancer was 41.6 months (range 0.9-152.7). The most common sites of BCBM were the cerebellum and parietal lobe. After BCBM excision, $75 \%$ of patients were administered whole brain radiotherapy, $44 \%$ received chemotherapy and $18 \%$ endocrine therapy. Eight HER2+ patients received trastuzumab or lapatinib. The median OS after BCBM excision was 18.3 months (range 0-99 months).

\section{Lymphocyte subpopulations, microglia/macrophages and reactive astrocyte infiltration in the brain microenvironment}

TIL (CD4+, CD8+) and macrophage/microglia (CD68+) infiltration was determined in $96 \%, 98 \%$ and $92 \%$ of

Table 2 Antibodies, dilutions and methods of evaluation

\begin{tabular}{|c|c|c|c|c|c|c|}
\hline Target & Manufacturer & Catalog number (type of staining) & Dilution & Incubation time & Control tissue & Method of evaluation \\
\hline PD-1 & Novus & NBP1-88104 (cytoplasmic) & 1:100 & $30^{\prime} \min$ & LN & SQ \\
\hline PD-L1 & AbD Serotec & AHP2128 (membranous/cytoplasmic) & $1: 50$ & $40^{\prime} \min$ & HSM & SQ \\
\hline PD-L2 & R\&D systems & AF1224 (membranous/cytoplasmic) & $1: 500$ & $30^{\prime} \min$ & LN & SQ \\
\hline CTLA4 & Santa Cruz & SC-376016 (cytoplasmic) & $1: 50$ & $40^{\prime} \min$ & LN & SQ \\
\hline GFAP & Dako & M0761 (cytoplasmic) & $\mathrm{RU}$ & $30^{\prime} \min$ & B & SQ \\
\hline CD4 & Dako & IR649 (membranous) & $\mathrm{RU}$ & $20^{\prime} \min$ & LN & Q \\
\hline CD8 & Dako & IR623 (cytoplasmic and membranous) & $\mathrm{RU}$ & $20^{\prime} \min$ & LN & Q \\
\hline CD68 & Dako & IR609 (cytoplasmic) & $\mathrm{RU}$ & $20^{\prime} \min$ & LN & Q \\
\hline
\end{tabular}

$R U$ ready to use, $S Q$ semiquantitative, $Q$ quantitative, $H S M$ human skeletal muscle, $L N$ lymph node, $B$ brain, $P D-1$ programmed death-1 receptor, $P D-L 1$ PD-1 ligand 1 , PD-L2 PD-L2 ligand 2, CTLA4 cytotoxic T cell antigen 4, GFAP glial fibrillary acid protein 


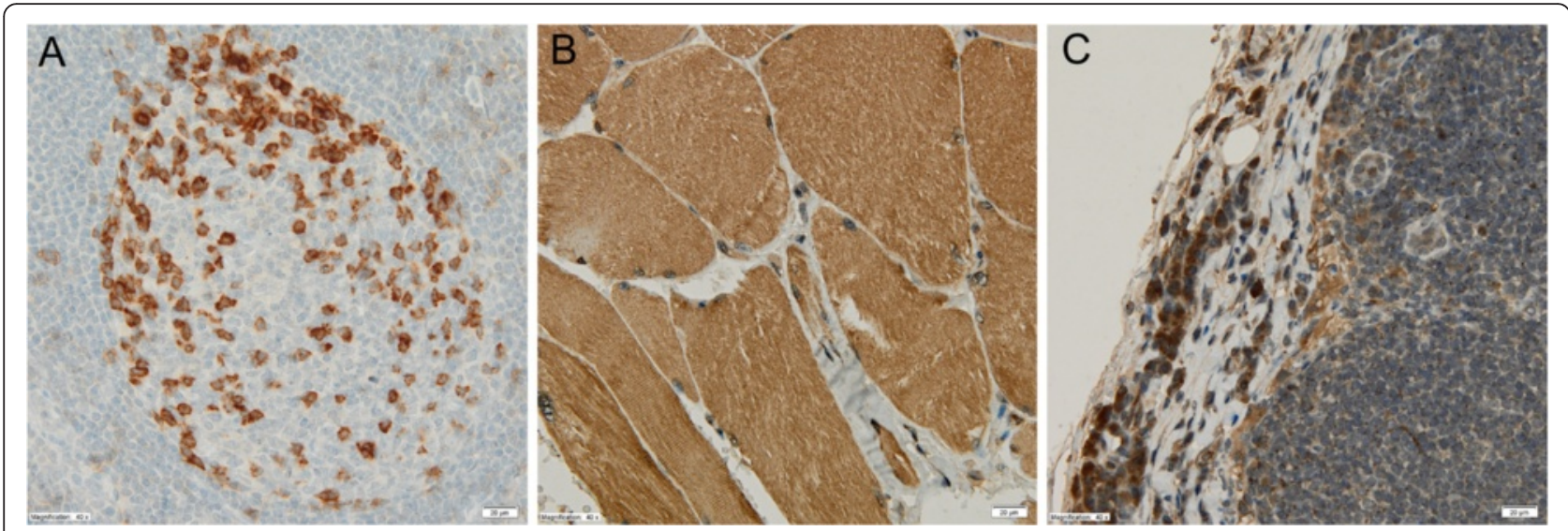

Fig. 1 Immunohistochemical positive control (original magnification $\times 400$ ). a Programmed cell death protein 1 receptor (PD-1): lymph node (germinal center in follicle). b Programmed cell death protein 1 receptor ligand (PD-L1): skeletal muscle. c PD-L2: lymph node (subcapsular sinus)

cases, respectively (Table 3). TILs were identified in both stromal and epithelial compartments of BCBM, but were generally much more abundant in the stroma (Fig. 2a, b). There was no CTLA4 expression on TILs (Fig. 2c). The median number (per $\mathrm{mm}^{2}$ ) of CD4+ TILs was 49

Table 3 Assessment of selected parameters of immune response in breast cancer brain metastasis and the brain microenvironment

\begin{tabular}{lll}
\hline Variable & Number & $\%$ \\
\hline Reactive astrocytes (glial fibrillary acid protein expression) & $83 / 84$ & 99 \\
No & 15 & 18 \\
Yes & 60 & 71 \\
No neuronal tissue & 8 & 10 \\
Stromal tumor infiltrating lymphocytes ${ }^{\text {a }}$ (CD4+) & $81 / 84$ & 96 \\
Median & 49 & \\
IQR & $23-121$ & \\
Stromal tumor infiltrating lymphocytes ${ }^{\text {a }}$ (CD8+) & $82 / 84$ & 98 \\
Median & 69 & \\
IQR & $38-127$ & \\
Microglia/macrophages ${ }^{\text {a }}$ (CD68+) & $77 / 84$ & 92 \\
Median & 76 & \\
IQR & $57-104$ & \\
PD-1 expression on tumor infiltrating lymphocytes & $74 / 84$ & 88 \\
No & 57 & 68 \\
Yes & 17 & 20 \\
Not determined & 10 & 12 \\
PD-L1 expression on BCBM & $78 / 84$ & 93 \\
H-score; mean (range) & $27.1(0-200)$ \\
PD-L2 expression on BCBM & $78 / 84$ & 93 \\
\hline
\end{tabular}

$I Q R$ interquartile range, $P D-1$ programmed cell death protein 1 receptor, $P D-L 1$ programmed cell death protein 1 receptor ligand 1, $P D-L 2$ programmed cell death protein 1 receptor ligand 2, BCBM breast cancer brain metastases. ${ }^{a}$ Density was scored at magnification $\times 400$ (ocular $\times 10$ with an objective $\times 40$ high-power field (HPF) per $1 \mathrm{~mm}^{2}$ (interquartile range (IQR) 23-121), of CD8+ TILs was 69 (IQR 38-127), and of CD68+ TILs was 76 (IQR 57-104) (Table 3$)$. CD4+ and CD8+ TILs were positively correlated $(r=0.48 ; P<0.001)$ and both were positively correlated with CD68+ cells $(r=0.23 ; P=0.043$ and $r=0.27, P=0.019$, respectively) (Table 4). GFAP, a biomarker of reactive astrocytes, was expressed in $71 \%$ of cases (Table 3). There was no correlation between GFAP expression and BCBM phenotype, TILs and CD68+ cell infiltration, or expression of PD-1 and its ligands.

\section{PD-1 expression on TILs and PD-L1, PD-L2 expression in BCBM}

PD-1 expression on TILs in BCBM was identified in 17 cases $(23 \%)$, more frequently in older patients (mean age at brain metastasis diagnosis in PD-1+ and PD-1groups 59 and 51 years, respectively; $P=0.003$ ), and in cases with HER2-amplified primary breast cancer. PD-1 expression was correlated positively with both TILs: CD4+ $(r=0.26 ; P=0.028)$ and CD8+ $(r=0.33 ; P=0.005$; Table 4). PD-1+ patients, compared to PD-1- patients had longer OS after BCBM excision (median 27.9 months (range $0.1-88.9)$ vs. 13.9 months (0.0-82.6), respectively; $P=0.02$ ) (Fig. 3a and Table 5). There was no correlation between expression of PD-1 on TILs and PD-1 ligands in BCBM (Table 4). PD-L1 and PD-L2 expression in BCBM was present in $41(53 \%)$ and 28 (36\%) cases, respectively, and was not related to BCBM phenotype. The mean expression for PD-L1 and PD-L2 (H-score) was 27 and 26, respectively (Table 3 ).

\section{Clinical outcomes}

There was no impact of previous systemic adjuvant therapy including trastuzumab on the analyzed immunological parameters in the brain. In HER2+ patients, the administration of trastuzumab before BCBM development did not affect CD4+ $(P=0.77)$ or CD8+ TILs $(P=0.17)$, CD68+ 


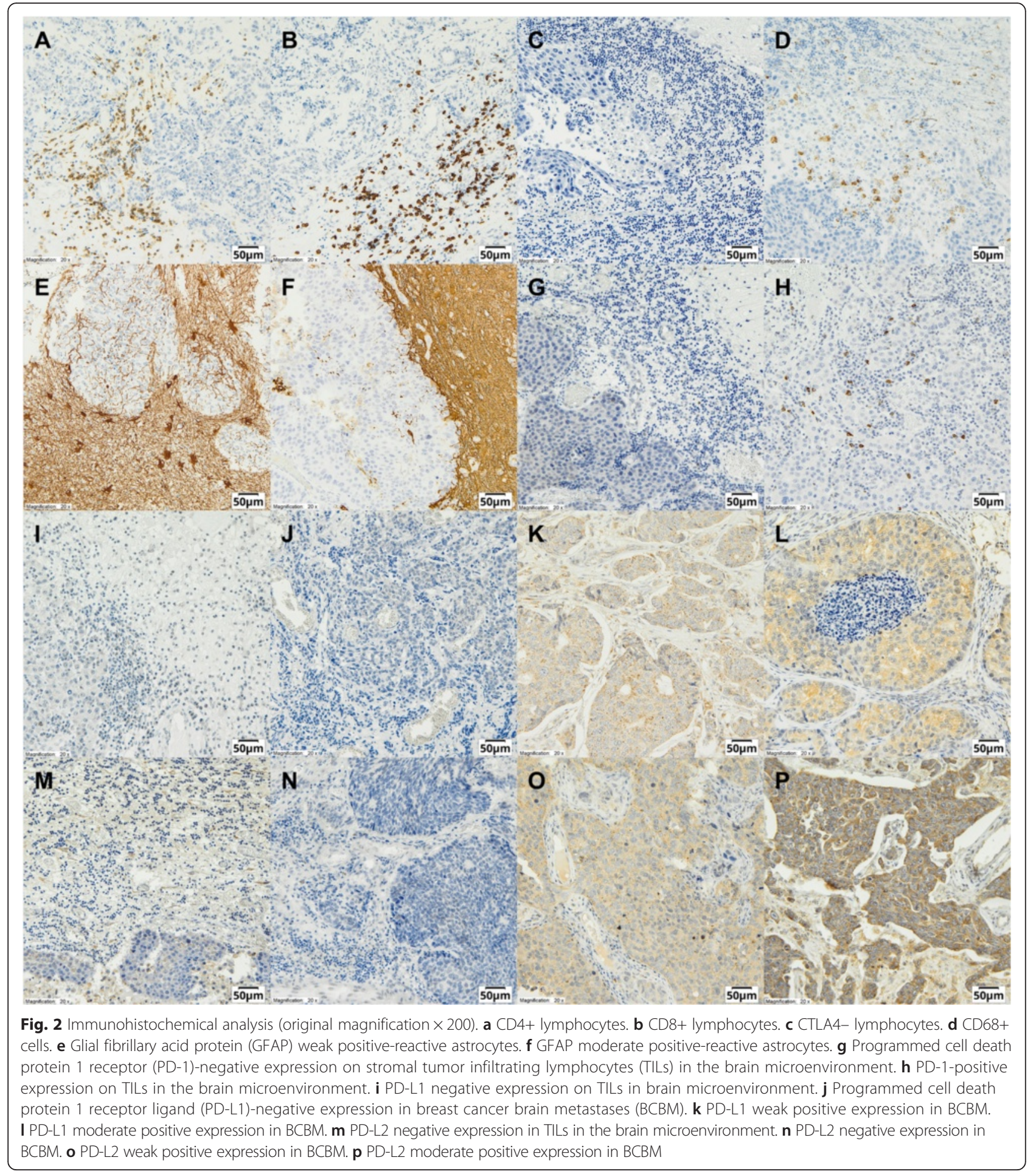

infiltration $(P=0.77)$, or expression of PD-1 $(P=0.85)$, PD-L1 $(P=0.86)$, or PD-L2 $(P=0.80)$. The univariate analysis of survival included all available clinicopathologic variables (the histology, grade and expression of ER, PR and HER2 in the primary tumor, phenotype of the primary tumor and BCBM, treatments administered prior to and after BCBM, type of first progression, dominant metastatic site and location of $\mathrm{BCBM}$ ) and all studied immune parameters (reactive astrocytes (GFAP), TILs (CD4+, CD8, microglia/macrophages (CD68+), PD-1 expression on TILs, and PD-L1 and PD-L2 expression on BCBM). The multivariate analysis included variables that were significant 
Table 4 Spearman's correlation (r) for continuous variables

\begin{tabular}{lllllll}
\hline Variable & & CD4 & CD8 & CD68 & PD-L1 & PD-L2 \\
\hline CD4 & $r$ & - & 0.48 & 0.23 & 0.12 & 0.20 \\
& $P$ & & $<0.001$ & 0.043 & 0.311 & 0.088 \\
CD8 & $r$ & 0.48 & - & 0.27 & 0.13 & 0.19 \\
& $P$ & $<0.001$ & & 0.019 & 0.264 & 0.100 \\
CD68 & $r$ & 0.23 & 0.27 & - & 0.09 & 0.19 \\
& $P$ & 0.043 & 0.019 & & 0.471 & 0.104 \\
PD-L1 & $r$ & 0.12 & 0.13 & 0.09 & - & 0.12 \\
& $P$ & 0.311 & 0.264 & 0.471 & & 0.317 \\
PD-L2 & $r$ & 0.20 & 0.19 & 0.19 & 0.12 & - \\
& $P$ & 0.088 & 0.100 & 0.104 & 0.317 & \\
PD-1 ${ }^{\text {a }}$ & $r$ & 0.26 & 0.33 & 0.06 & -0.04 & 0.13 \\
& $P$ & 0.028 & 0.005 & 0.617 & 0.742 & 0.267 \\
\hline
\end{tabular}

$P D$-1 programmed cell death protein 1 receptor, $P D-L 1$ programmed cell death protein 1 receptor ligand. ${ }^{a}$ Categorical variable

$(P<0.05)$ in the univariate analysis (Table 5$)$. In this analysis, favorable factors for survival after BCBM excision included PD-1 expression on TILs (hazard ratio $(\mathrm{HR})=0.3$ (0.1-0.7); $P=0.003$ ) (Fig. 3a) and CD68+ cell infiltration $(\mathrm{HR}=0.2(0.1-0.5) ; P<0.001)$ (Fig. 3b), brain radiotherapy
$(\mathrm{HR}=0.1(0.1-0.3) ; P<0.001)$, and endocrine therapy after the development of BCBM $(\mathrm{HR}=0.1(0.1-0.3) \quad P<0.001$; Table 5). Adverse prognostic factors included a hormone receptor-/HER2+ primary tumor phenotype $(\mathrm{HR}=2.6$ (1.3-5.5); $P=0.01)$ and HER2 expression in BCBM (HR = 4.9 (1.3-19.2); $P=0.01)$.

\section{Discussion}

We have presented a comprehensive analysis of several immune parameters in BCBM. This is also the largest study analyzing the clinical relevance of these parameters. Our data indicate that the PD-1/PD-L axis may play an important role in the local immune response accompanying BCBM. Furthermore, we observed that the infiltration of the brain microenvironment by CD4+ and CD8+ lymphocytes, macrophages/microglia and reactive astrocytes is a common occurrence, and these features are probably independent of BCBM phenotype and previous systemic therapies.

There are two leading hypotheses explaining PD-L1 expression in tumors: the first based on the innative, and the second on the adaptive model [20]. In the innative model, PD-L1 expression is independent of the tumor microenvironment and is influenced by intrinsic cell
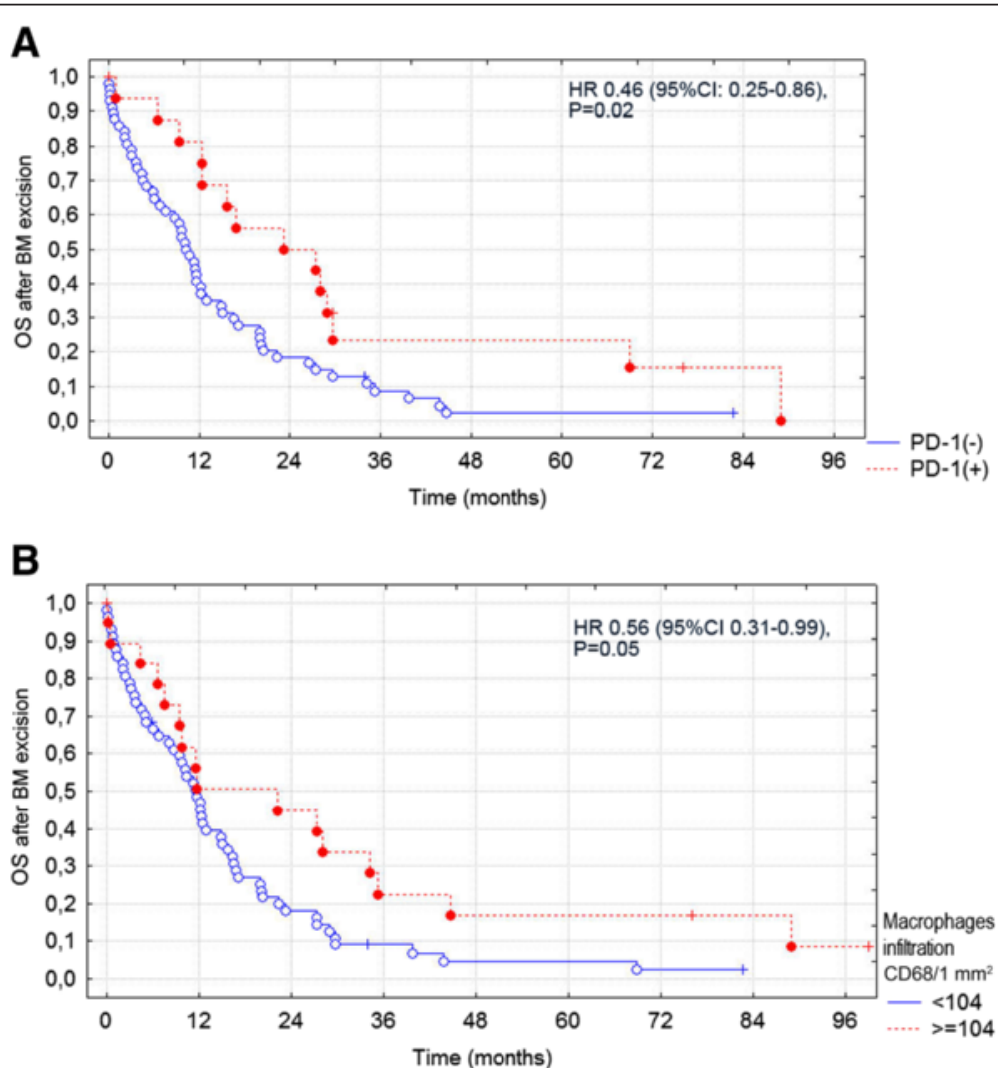

Fig. 3 Kaplan-Meier curves for overall survival (OS) after excision of breast cancer bone metastases (BM). a Programmed cell death protein 1 receptor (PD-1)-positive vs. PD-1-negative stromal tumor infiltrating lymphocytes (TILs) in the brain microenvironment. b high vs. low macrophage/microglia infiltration (CD68+) in the brain microenvironment. HR hazard ratio 
Table 5 Factors impacting overall survival after excision of breast cancer brain metastases (significant in univariate and multivariate analysis)

\begin{tabular}{|c|c|c|c|c|}
\hline \multirow[t]{2}{*}{ Variable } & \multicolumn{2}{|c|}{ Univariate analysis } & \multicolumn{2}{|c|}{ Multivariate analysis } \\
\hline & $\mathrm{HR}(95 \% \mathrm{Cl})$ & $P$ & $\mathrm{HR}(95 \% \mathrm{Cl})$ & $P$ \\
\hline Primary tumor phenotype HER2-enriched, yes vs. no & $3.0(1.1-9.9)$ & 0.033 & $2.6(1.3-5.5)$ & 0.010 \\
\hline Radiotherapy after BCBM, yes vs. no & $0.1(0.0-0.2)$ & $<0.001$ & $0.1(0.1-0.3)$ & $<0.001$ \\
\hline Endocrine therapy after BCBM excision, yes vs. no & $0.1(0.0-0.2)$ & $<0.001$ & $0.1(0.0-0.3)$ & $<0.001$ \\
\hline HER2 IHC expression in BCBM, yes vs. no & $6.5(1.5-27.8)$ & 0.011 & $4.9(1.3-19.2)$ & 0.020 \\
\hline PD-1 expression on TILs in brain, yes vs. no & $0.5(0.3-0.9)$ & 0.015 & $0.3(0.1-0.7)$ & 0.003 \\
\hline Microglia/macrophages infiltration, $\geq 104$ vs. $<104$ per mm² & $0.6(0.3-1.0)$ & 0.049 & $0.2(0.1-0.5)$ & $<0.001$ \\
\hline
\end{tabular}

HR hazard ratio, HER2 human epidermal growth factor receptor 2, BCBM breast cancer brain metastases, IHC immunohistochemical analysis TILs stromal tumor-infiltrating lymphocytes, $P D-1$ programmed death receptor type 1

signaling pathways. The adaptive model assumes that TILs are the key factor driving PD-L1 expression and that immune resistance is exerted by tumor cells in response to endogenous antitumor activity [13, 21-23]. This allows tumor cells to escape immune destruction despite endogenous antitumor immune reactions. Previous studies showed that the PD-1/PD-L axis regulates the induction and maintenance of peripheral tolerance and protects tissues from autoimmune attack (reviewed by Jin et al. [23]). PD-L1 expression in the CNS was identified in glioblastoma and in human brain metastases from melanoma, renal cell carcinoma, lung cancer, colon cancer, and breast cancer, and the PD-1/PD-L1 axis in primary brain lymphomas [16-19]. Here, we demonstrated that PD-L1 and PD-L2 expression is also a common occurrence in $\mathrm{BCBM}$, irrespective of the primary tumor and brain metastasis phenotype.

Recently, PD-L1 expression was found to be more common in primary triple-negative breast cancer [24, 25], but we did not find such a correlation in BCBM. However, PD-L1 expression is a dynamic process in normal conditions and is influenced by cytokines, such as interferon (INF)- $\gamma$ [26]. In turn, PD-L1 expression in tumor cells may be influenced by systemic therapy. Moreover, biopsy timinig (at diagnosis vs. at progression) to determine PD-L1 expression may be critical in patient selection for immune checkpoint inhibitors or other experimental therapies [27]. Hitherto, there are no data on the comparison of PD-L expression in primary breast cancer and in the corresponding BCBM. In a recent study by Berghoff et al. [28] there was no correlation between PD-L1 expression in brain metastases from various solid tumors and TIL density, and the authors also postulated that the density of $\mathrm{CD} 3+, \mathrm{CD} 8+$ and CD45RO+ TILs, and the calculated immunoscore, are positively correlated with survival. In the recent study by Harter et al. [19], which included several tumor types, there was no significant prognostic impact of TIL expression in brain metastases in the entire population, and there was a strong trend towards better survival in brain metastases from melanoma with high levels of PD-L1 [19].
The biological role of PD-L2 is less well-understood. Recent studies showed that PD-L2 can be induced on antigen-presenting cells, such as macrophages, dendritic cells, $\mathrm{T}$ cells and a wide variety of non-immune cells, depending on the microenvironmental stimuli [29]. Some studies suggest an adverse prognostic impact of PD-L expression, whereas others, including ours, did not find such a relationship, or even showed the opposite $[18,19$, $30,31]$. These differences may likely be due to different methods used for the detection of ligand expression and the lack of standardized criteria for assessment of PD-L expression.

PD-1 is an inhibitory co-receptor expressed on activated and exhausted T cells [13-15, 32, 33]. We demonstrated that PD-1 expression on TILs in BCBM is independently associated with increased OS. However, our study included patients with limited numbers of $\mathrm{BCBM}$ eligible for resection and with good performance status, and most had controlled extracranial disease. Hence it is unknown whether this observation applies to all patients with BCBM. Although PD-1 expression correlated with $\mathrm{CD} 4+$ and CD8+ TILs, increased OS was not directly related to the mere presence of TILs, an observation suggesting the importance of preexisting active immunity. Interestingly, in the abovementioned study by Harter et al. [19], PD-1+ lymphocytes and the ratio between PD-1 and CD8+ cells were higher in smaller than in larger metastases. This finding may indicate that in smaller metastases the lymphocytic immune response is activated but functionally impaired. It is also possible that $\mathrm{T}$ cells may control the tumor size transiently before becoming exhausted.

Data on the prognostic value of PD-1 expression on TILs in various malignancies are scarce and inconsistent. In primary renal cell carcinoma, on univariate analysis PD-1 expression on mononuclear immune cell infiltrates was found to increase the risk of cancer-specific death and overall mortality [34]. However, in this study PD-1 was associated with more advanced disease, the presence of coagulation, tumor necrosis, and sarcomatoid differentiation. 
Hence, this feature may be associated with more aggressive disease characteristics rather than be an adverse prognostic factor per se. Similarly, in operable breast cancer, PD-1+ immune cell infiltration in the primary tumor is reported to correlate with shorter survival [35]. In contrast to these reports, in a series of recent studies the PD-1/PD-L1 axis had a favorable effect, supporting the role of preexisting antitumor immunity $[5,36,37]$. Notably, all these studies relate to primary tumors, whereas we included BCBM, in which immune mechanisms may be substantially different due to the immune privilege of the CNS [7, 37]. Nonetheless, evidence of a favorable prognostic role of PD-1 expression on TILs in BCBM should be considered cautiously and warrants confirmation.

We did not observe a relationship between expression of PD-1 on TILs, and PD-Ls expression in BCBM, and neither did we find major differences across breast cancer phenotypes, except for more common PD-1 expression in HER2-amplified primary tumors. According to the adaptive resistance hypothesis, cancer cells can upregulate the expression of PD-L1 after encountering T cells, mostly via IFN- $\gamma$. However, there are data suggesting that cancer cells also express PD-L1 by an intrinsic, INF- $\gamma$ independent mechanism [38, 39]. Further, some genetic abnormalities, such as a loss of phosphatase and tensin homolog in glioma or triple-negative breast cancer, and epidermal growth factor receptor mutations in lung cancer, can directly upregulate PD-L1 on cancer cells [24, 40, 41]. On the other hand, it has been speculated that the local CNS microenviroment may in some way suppress the INF- $\gamma$ mediated response, thus, paradoxically decreasing brain tissue damage [37]. Interestingly, only an undetermined fraction of lymphocyte infiltration dies through the interaction with the PD-1/PD-L axis. Additionally, there are non-PD-1 costimulatory receptors for PD-L, which are responsible for the enhanced effector function of PD-Lexpressing tumor cells $[42,43]$.

In this series, besides PD-1 expression, macrophages/ microglia infiltration was also found to be associated with significantly longer survival after the excision of BCBM. The macrophages/microglia play a key role in the development of innate and adaptive immune response in the brain [44]. These cells are perceived as a main source of proinflammatory cytokines and more as antigen-presenting cells, and actively participate in the $\mathrm{T}$ cell restimulation $[8,9,44]$. The limitation of our study was identifying macrophages/ microglia exclusively by CD68 staining, as other markers (such as CD14, CD11b, and/or MHC-II) might have likely provided more data on the prognostic role of these cells.

Some preclinical studies suggest a potential role for immune checkpoint inhibitors in mammary tumors, particularly HER2+ phenotypes. Combining trastuzumab with inhibitors of negative $\mathrm{T}$ cell regulation, such as antiPD-1, anti-PD-L1 or anti-CTLA4 antibodies, may increase antitumor efficacy $[45,46]$. In HER2+ patients receiving trastuzumab, PD-1 inhibition stimulates CD8+ cells producing INF- $\gamma$, and may increase the therapeutic effect of this antibody [46]. However, in our study trastuzumab administered before the development of BCBM did not affect the expression of TILs, CD68+ cell infiltration, or PD-1 and its ligands in BCBM. The brain microenvironment may promote HER2 expression via secretion of specific cytokines, such as neuregulin [47]. We recently demonstrated that expression of quantitative HER2 and p95 - its truncated, constitutively active form - is significantly increased in BCBM compared to primary breast cancers [48]. In that study, p95 expression in brain metastases also correlated with poorer clinical outcome.

Currently, PD-1 inhibitors, such as pembrolizumab and nivolumab, are a subject of clinical investigation in non-small cell lung cancer and melanoma with brain metastases (NCT02085070, NCT02320058), whereas no data are available for anti-PD therapies in BCBM. Hence, there is a rationale for investigation into boosting the host antitumor immune response by inhibiting the inhibitors (via increasing lymphocyte influx to the brain or inhibiting PD-L expression in tumor cells) also in BCBM. Pembrolizumab has shown promising effects and a good safety profile in PD-L1-positive advanced triple-negative breast cancer (KEYNOTE-012 study; NCT01848834) and in heavily pretreated ER+/HER2breast cancer (KEYNOTE-028 study; NCT02054806) $[49,50]$. PD-L1 inhibitors, atezolizumab (MPDL3280A) and avelumab (MSB0010718C) appear to be particularly active in triple-negative breast cancer [51, 52]. Several ongoing clinical trials are investigating other immune checkpoint inhibitors in both in locally advanced and/ or metastatic breast cancer and in the adjuvant setting (reviewed in Chawla et al. [53]).

\section{Conclusions}

We demonstrated an important role for an activated preexisting immune response in a relatively large group of patients with BCBM. However, we are aware of some limitations of this study, including its retrospective nature, small number of cases in particular subsets, and the lack of assay standardization in terms of sampling and other technical issues. Thus, our findings warrant confirmation in further investigations.

\section{Abbreviations \\ BCBM: breast cancer brain metastases; BM: brain metastases; CNS: central nervous system; ERa: estrogen receptor alpha; FFPE: formalin-fixed, paraffin-embedded; GFAP: glial fibrillary acid protein; HER2: human epidermal growth factor receptor 2; IHC: immunohistochemistry; INF: interferon; IQR: interquartile range; OS: overall survival; PD-1: programmed cell death protein 1 receptor; PD-L: programmed cell death protein 1 receptor ligand; PR: progesterone receptor; TILs: stromal tumor infiltrating lymphocytes.}

Competing interests

The authors declare that they have no competing interests. 


\section{Authors' contributions}

RD was the principal investigator who conceived, coordinated and oversaw the study and wrote the manuscript. RP carried out the immunoassays and data analysis and drafted the manuscript. BR, TM, and TT participated in the collection of clinical data, performed data analysis, and drafted the manuscript. BJ, BCA, WO, and WK participated in the preparation of the biological samples, performed data analysis, and drafted the manuscript. WAO, EKW, and AK participated in the collection of clinical data, performed data analysis, and drafted the manuscript. SL participated in data analysis and drafted the manuscript. WB carried out the immunoassays and data analysis and drafted the manuscript. JJ conceived, coordinated and oversaw the study, and wrote the manuscript. All authors read and approved the final manuscript.

\section{Authors' information}

Renata Duchnowska, MD, PhD, oncologist; Rafał Pęksa, MD, PhD, pathologist; Barbara Radecka, MD, PhD, oncologist; Tomasz Mandat, MD, PhD, neurosurgeon; Tomasz Trojanowski, MD, PhD, neurosurgeon; Bożena Jarosz, MD, PhD, pathologist; Bogumiła Czartoryska-Arłukowicz, MD, oncologist; Wojciech P. Olszewski, MD, PhD pathologist; Waldemar Och, MD, neurosurgeon; Ewa Kalinka-Warzocha, MD, PhD, oncologist; Wojciech Kozłowski, MD, PhD, pathologist; Anna Kowalczyk, MD, PhD, oncologist; Sherene Loi, MD, PhD, oncologist; Wojciech Biernat, MD, PhD, pathologist; Jacek Jassem, MD, PhD, oncologist.

\section{Acknowledgements}

This work was supported by a scientific grant from the Polish Society of Oncology.

\section{Author details}

'Department of Oncology, Military Institute of Medicine, Szaserów St 128, 04-141 Warsaw, Poland. ${ }^{2}$ Department of Pathology, Medical University of Gdańsk, 7 Dębinki St, 80-211 Gdańsk, Poland. ${ }^{3}$ Department of Oncology, Regional Oncology Center, 66a Katowicka St, 45-060 Opole, Poland. ${ }^{4}$ Department of Neurosurgery, Oncology Center-Institute, 5 Roentgena St, 02-781 Warsaw, Poland. ${ }^{5}$ Department of Neurosurgery, Medical University of Lublin, 1 Al. Racławickie, 20-059 Lublin, Poland. 'Department of Oncology, Regional Oncology Center, 12 Ogrodowa St, 15-027 Białystok, Poland. ${ }^{7}$ Department of Pathology, Oncology Center-Institute, 5 Roentgena St, 02-781 Warsaw, Poland. ${ }^{8}$ Department of Neurosurgery, Regional Hospital, 18 Żołnierska St, 10-561 Olsztyn, Poland. ${ }^{9}$ Department of Oncology, Regional Oncology Center, 62 Pabianicka St, 93-513 Łódź, Poland. ${ }^{10}$ Department of Pathology, Military Institute of Medicine, Szaserów St 128, 04-141 Warsaw, Poland. ${ }^{11}$ Department of Oncology and Radiotherapy, Medical University of Gdańsk, 7 Dębinki St, 80-211 Gdańsk, Poland. ${ }^{12}$ Division of Cancer Medicine and Research, Peter MacCallum Cancer Centre, Locked Bag 1, A'Beckett Street, East Melbourne, VIC 8006, Australia.

\section{Received: 8 December 2015 Accepted: 4 April 2016} Published online: 27 April 2016

\section{References}

1. Adams S, Gray RJ, Demaria S, Goldstein L, Perez EA, Shulman LN, et al. Prognostic value of tumor-infiltrating lymphocytes in triple-negative breast cancers from two phase III randomized adjuvant breast cancer trials: ECOG 2197 and ECOG 1199. J Clin Oncol. 2014;32:2959-66.

2. Dieci MV, Criscitiello C, Goubar A, Viale G, Conte P, Guarneri V, et al. Prognostic value of tumor-infiltrating lymphocytes on residual disease after primary chemotherapy for triple-negative breast cancer: a retrospective multicenter study. Ann Oncol. 2014;25:611-8.

3. Loi S, Michiels S, Salgado R, Sirtaine $N$, Jose V, Fumagalli $D$, et al. Tumor infiltrating lymphocytes are prognostic in triple negative breast cancer and predictive for trastuzumab benefit in early breast cancer: results from the FinHER trial. Ann Oncol. 2014;25:1544-50.

4. Loi S, Sirtaine N, Piette F, Salgado R, Viale G, Van Eenoo F, et al. Prognostic and predictive value of tumor-infiltrating lymphocytes in a phase III randomized adjuvant breast cancer trial in node-positive breast cancer comparing the addition of docetaxel to doxorubicin with doxorubicinbased chemotherapy: BIG 02-98. J Clin Oncol. 2013;31:860-7.

5. Denkert C, von Minckwitz G, Brase JC, Sinn BV, Gade S, Kronenwett R, et al. Tumor-infiltrating lymphocytes and response to neoadjuvant chemotherapy with or without carboplatin in human epidermal growth factor receptor 2-positive and triple-negative primary breast cancers. J Clin Oncol. 2015;33:983-91.

6. Perez EA, Ballman KV, Tenner KS, Thompson EA, Badve SS, Bailey H, et al. Association of stromal tumor infiltrating lymphocytes with recurrence-free survival in the N9831 adjuvant trial in patients with early-stage HER2-positive breast cancer. JAMA Oncol. 2015;15:1-9.

7. Muldoon LL, Alvarez Jl, Begley DJ, Boado RJ, Del Zoppo GJ, Doolittle ND, et al. Immunologic privilege in the central nervous system and the blood-brain barrier. J Cereb Blood Flow Metab. 2013;33:13-21.

8. Hudson LC, Bragg DC, Tompkins MB, Meeker RB. Astrocytes and microglia differentially regulate trafficking of lymphocyte subsets across brain endothelial cells. Brain Res. 2005;1058:148-60.

9. Fitzgerald DP, Palmieri D, Hua E, Hargrave E, Herring JM, Qian Y, et al. Reactive glia are recruited by highly proliferative brain metastases of breast cancer and promote tumor cell colonization. Clin Exp Metastasis. 2008;25:799-810.

10. Lin Q, Balasubramanian K, Fan D, Kim SJ, Guo L, Wang H, et al. Reactive astrocytes protect melanoma cells from chemotherapy by sequestering intracellular calcium through gap junction communication channels. Neoplasia. 2010;12:748-54.

11. Müller M, Carter SL, Hofer MJ, Manders P, Getts DR, Getts MT, et al. CXCR3 signaling reduces the severity of experimental autoimmune encephalomyelitis by controlling the parenchymal distribution of effector and regulatory $T$ cells in the central nervous system. J Immunol. 2007;179:2774-86.

12. Wilson EH, Weninger W, Hunter CA. Trafficking of immune cells in the central nervous system. J Clin Invest. 2010;120:1368-79.

13. Keir ME, Butte MJ, Freeman GJ, Sharpe AH. PD-1 and its ligands in tolerance and immunity. Annu Rev Immunol. 2008;26:677-704.

14. Rahbar R, Lin A, Ghazarian M, Yau HL, Paramathas S, Lang PA, et al. B7-h4 expression by nonhematopoietic cells in the tumor microenvironment promotes antitumor immunity. Cancer Immunol Res. 2015;3:184-95.

15. Gatalica Z, Snyder C, Maney T, Ghazalpour A, Holterman DA, Xiao N, et al. Programmed cell death 1 (PD-1) and its ligand (PD-L1) in common cancers and their correlation with molecular cancer type. Cancer Epidemiol Biomarkers Prev. 2014;23:2965-70.

16. Berghoff AS, Ricken G, Widhalm G, Rajky O, Hainfellner JA, Birner $P$, et al. PD1 (CD279) and PD-L1 (CD274, B7H1) expression in primary central nervous system lymphomas (PCNSL). Clin Neuropathol. 2014;33:42-9.

17. Berghoff AS, Ricken G, Widhalm G, Rajky O, Dieckmann K, Birner P, et al. Tumour-infiltrating lymphocytes and expression of programmed death ligand 1 (PD-L1) in melanoma brain metastases. Histopathology. 2015;66:289-99.

18. Berghoff AS, Kiesel B, Widhalm G, Rajky O, Ricken G, Wöhrer A, et al. Programmed death ligand 1 expression and tumor-infiltrating lymphocytes in glioblastoma. Neuro Oncol. 2015;8:1064-75.

19. Harter PN, Bernatz S, Scholz A, Zeiner PS, Zinke J, Kiyose M, et al. Distribution and prognostic relevance of tumor-infiltrating lymphocytes (TILs) and PD-1/PD-L1 immune checkpoints in human brain metastases. Oncotarget. 2015;6:40836-49.

20. Pardoll DM. The blockade of immune checkpoints in cancer immunotherapy. Nat Rev Cancer. 2012;12:252-64.

21. Taube JM, Anders RA, Young GD, Xu H, Sharma R, McMiller TL, et al. Colocalization of inflammatory response with B7-h1 expression in human melanocytic lesions supports an adaptive resistance mechanism of immune escape. Sci Transl Med. 2012;4:127ra37.

22. Konishi J, Yamazaki K, Azuma M, Kinoshita I, Dosaka-Aita H, Nishimura M. B7-H1 expression on non small cell lung cancer cells and its relationship with tumor-infiltrating lymphocytes and their PD-1 expression. Clin Cancer Res. 2004;10:5094-100.

23. Jin HT, Ahmed R, Okazaki T. Role of PD-1 in regulating T-cell immunity. Curr Top Microbiol Immunol. 2011;350:17-37.

24. Mittendorf EA, Philips AV, Meric-Bernstam F, Qiao N, Wu Y, Harrington S, et al. PD-L1 expression in triple-negative breast cancer. Cancer Immunol Res. 2014;2:361-70.

25. Karasar P, Esendagli G. T helper responses are maintained by basal-like breast cancer cells and confer to immune modulation via upregulation of PD-1 ligands. Breast Cancer Res Treat. 2014;145:605-14.

26. Abiko K, Matsumura N, Hamanishi J, Horikawa N, Murakami R, Yamaguchi K, et al. IFN- $\gamma$ from lymphocytes induces PD-L1 expression and promotes progression of ovarian cancer. Br J Cancer. 2015;112:1501-9.

27. Leventakos K, Mansfield AS. Reflections on immune checkpoint inhibition in non-small cell lung cancer. Transl Lung Cancer Res. 2014;3:411-3.

28. Berghoff AS, Fuchs E, Ricken G, Mlecnik B, Bindea G, Spanberger T, et al. Density of tumor-infiltrating lymphocytes correlates with extent of brain 
edema and overall survival time in patients with brain metastases. Oncolmmunology. 2016. doi:10.1080/2162402X.2015.1057388

29. Ghiotto M, Gauthier L, Serriari N, Pastor S, Truneh A, Nunès JA, et al. PD-L1 and PD-L2 differ in their molecular mechanisms of interaction with PD-1. Int Immunol. 2010;22:651-60.

30. Gettinger SN, Horn L, Gandhi L, Spigel DR, Antonia SJ, Rizvi NA, et al. Overall survival and long-term safety of nivolumab(anti-programmed death 1 antibody, BMS-936558, ONO-4538) in patients with previously treated advanced non-small-cell lung cancer. J Clin Oncol. 2015;33:2004-12.

31. Zhang Y, Huang S, Gong D, Qin Y, Shen Q. Programmed death-1 upregulation is correlated with dysfunction of tumor-infiltrating CD8+ T lymphocytes in human non small cell lung cancer. Cell Mollmmunol. 2010;7:389-95.

32. Ishida Y, Agata Y, Shibahara K, Honjo T. Induced expression of PD-1, a novel member of the immunoglobulin gene superfamily, upon programmed cell death. EMBO J. 1992;11:3887-95.

33. Topalian SL, Hodi FS, Brahmer JR, Gettinger SN, Smith DC, McDermott DF, et al. Safety, activity, and immune correlates of anti-PD-1 antibody in cancer. N Engl J Med. 2012;366:2443-54.

34. Thompson RH, Gillett MD, Cheville JC, Lohse CM, Dong H, Webster WS, et al. Costimulatory B7-H1 in renal cell carcinoma patients: indicator of tumor aggressiveness and potential therapeutic target. Proc Natl Acad Sci U S A. 2004;101:17174-9.

35. Sun S, Fei X, Mao Y, Wang X, Garfield DH, Huang O, et al. PD-1(+) immune cell infiltration inversely correlates with survival of operable breast cancer patients. Cancer Immunol Immunother. 2014;63:395-406.

36. Herbst RS, Soria JC, Kowanetz M, Fine GD, Hamid O, Gordon MS, et al. Predictive correlates of response to the anti-PD L1 antibody MPDL3280A in cancer patients. Nature. 2014;515:563-7.

37. Male D. Modes of immune response. In: Male D, Brostoff J, Roth D, Roitt I, editors. Immunology. Elselvier Ltd; 2006. p. 127-249.

38. Soliman H, Khalil F, Antonia S. PD-L1 expression is increased in a subset of basal type breast cancer cells. PLoS One 2014;9:e88557.

39. Velcheti V, Schalper KA, Carvajal DE, Anagnostou VK, Syrigos KN, Sznol M, et al. Programmed death ligand-1 expression in non-small cell lung cancer. Lab Invest. 2014;94:107-16.

40. Parsa AT, Waldron JS, Panner A, Crane CA, Parney IF, Barry JJ, et al. Loss of tumor suppressor PTEN function increases B7-H1 expression and immunoresistance in glioma. Nat Med. 2007;13:84-8.

41. Akbay EA, Koyama S, Carretero J, Altabef A, Tchaicha JH, Christensen CL, et al. Activation of the PD-1 pathway contributes to immune escape in EGFRdriven lung tumors. Cancer Discov. 2013;3:1355-63.

42. Shin T, Kennedy G, Gorski K, Tsuchiya H, Koseki H, Azuma M, et al. Cooperative B7-1/2 (CD80/CD86) and B7-DC costimulation of CD4+ T cells independent of the PD-1 receptor. J Exp Med. 2003;198:31-8.

43. Liu X, Gao JX, Wen J, Yin L, Li O, Zuo T, et al. B7DC/PDL2 promotes tumor immunity by a PD-1-independent mechanism. J Exp Med. 2003; 197:1721-30.

44. Hanisch UK, Kettenmann H. Microglia: active sensor and versatile effector cells in the normal and pathologic brain. Nat Neurosci. 2007;10:1387-94.

45. Park S, Jiang Z, Mortenson ED, Deng L, Radkevich-Brown O, Yang X, et al. The therapeutic effect of anti-HER2/neu antibody depends on both innate and adaptive immunity. Cancer Cell. 2010;18:160-70.

46. Stagg J, Loi S, Divisekera U, Ngiow SF, Duret H, Yagita H, et al. Anti-ErbB-2 $\mathrm{mAb}$ therapy requires type I and II interferons and synergizes with anti-PD-1 or anti-CD137 mAb therapy. Proc Natl Acad Sci U S A. 2011;108:7142-7.

47. Da Silva L, Simpson PT, Smart CE, Cocciardi S, Waddell N, Lane A, et al. HER3 and downstream pathways are involved in colonization of brain metastases from breast cancer. Breast Cancer Res. 2010;12:R46.

48. Duchnowska R, Sperinde J, Chenna A, Huang W, Weidler JM, Winslow J, et al. Quantitative HER2 and p95HER2 levels in primary breast cancers and matched brain metastases. Neuro Oncol. 2015;9:1241-9.

49. Nanda R, Chow LQ, Dees EC, Berger R, Gupta S, Geva R, et al. A phase lb study of pembrolizumab (MK-3475) in patients with advanced triplenegative breast cancer. Cancer Res. 2015;75 Suppl 9:S1-09.

50. Rugo HS, Delord J-P, Im S-A, Ott PA, Piha-Paul SA, Bedard PL, et al. Preliminary efficacy and safety of pembrolizumab (MK-3475) in patients with PD-L1-positive, estrogen receptor-positive (ER+)/HER2-negative advanced breast cancer enrolled in KEYNOTE-028. Cancer Res. 2016;76 Suppl 4:S5-07.
51. Emens LA, Braiteh FS, Cassier PA, Delord J, Eder JP, Shen X, et al. Inhibition of PD-L1 by MPDL3280A leads to clinical activity in patients with metastastic triple-negative breast cancer. Cancer Res. 2015;75 Suppl 9:PD1-6.

52. Dirix LY, Takacs I, Nikolinakos P, Jerusalem G, Arkenau H-T, Hamilton EP, et al. Avelumab (MSB0010718C), an anti-PD-L1 antibody, in patients with locally advanced or metastatic breast cancer: A phase lb JAVELIN solid tumor trial. Cancer Res. 2016;76 Suppl 4:S1-04.

53. Chawla A, Philips AV, Alatrash G, Mittendorf E. Immune checkpoints: A therapeutic target in triple negative breast cancer. Oncoimmunology. 2014;3:e28325.

\section{Submit your next manuscript to BioMed Central and we will help you at every step:}

- We accept pre-submission inquiries

- Our selector tool helps you to find the most relevant journal

- We provide round the clock customer support

- Convenient online submission

- Thorough peer review

- Inclusion in PubMed and all major indexing services

- Maximum visibility for your research

Submit your manuscript at www.biomedcentral.com/submit
C Biomed Central 